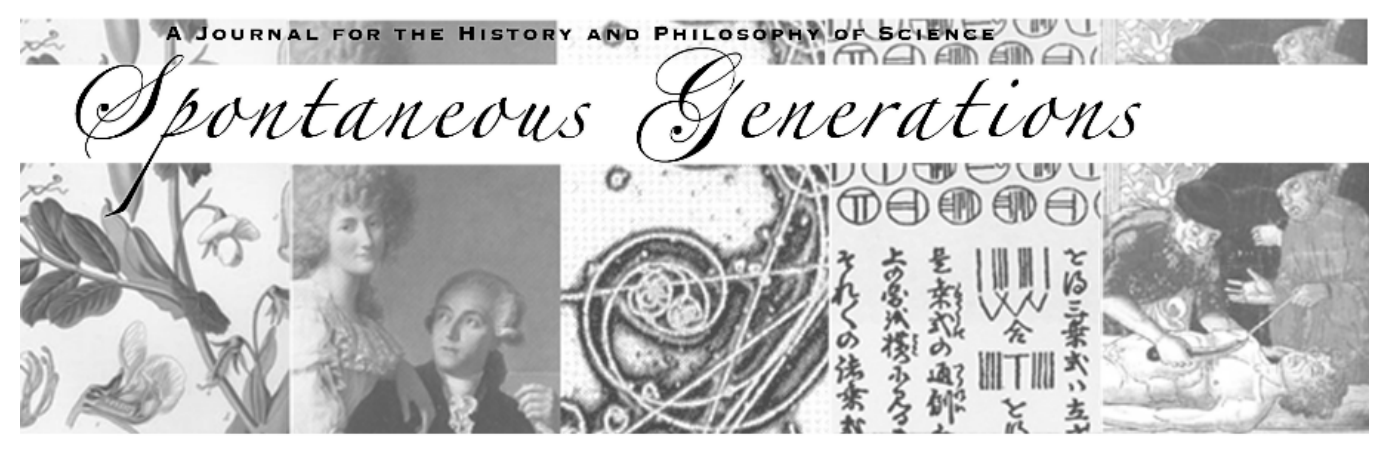

\title{
What are climate scientists to do?
}

\section{Author(s): Evelyn Fox Keller}

Source: Spontaneous Generations: A Journal for the History and Philosophy of Science, Vol. 5, No. 1 (2011) 19-26.

Published by: The University of Toronto

DOI: $\underline{10.4245 / \text { sponge.v5i1.15165 }}$

\section{EDITORIAL OFFICES}

Institute for the History and Philosophy of Science and Technology

Room 316 Victoria College, 91 Charles Street West

Toronto, Ontario, Canada M5S 1K7

hapsat.society@utoronto.ca

Published online at jps.library.utoronto.ca/index.php/SpontaneousGenerations ISSN 19130465

Founded in 2006, Spontaneous Generations is an online academic journal published by graduate students at the Institute for the History and Philosophy of Science and Technology, University of Toronto. There is no subscription or membership fee. Spontaneous Generations provides immediate open access to its content on the principle that making research freely available to the public supports a greater global exchange of knowledge. 


\title{
What are climate scientists to do?*
}

\author{
Evelyn Fox Keller ${ }^{\dagger}$
}

\begin{abstract}
The campaign to discredit predictions of man-made global warming-originally organized by readily identifiable vested interests-has
\end{abstract} by now recruited a large popular constituency of declared "skeptics" increasingly disposed to "take a stand": some of them opposed to government regulation in general, some resistant to any claims to intellectual authority (perhaps especially scientific), and some mobilized by a version of the right to individual freedom of opinion. As a result, confidence in the expertise of scientists has reached an all time low: Internet sites, radio talk shows, and television channels preferentially transmit "contrarian" attacks on the credibility of climate scientists. Even our most responsible newspapers and journals, in their very commitment to the traditional ethic of "balance," sometimes contribute to the widespread misimpression that climate scientists are deeply divided about both the extent of the dangers we face and the relevance of human activity to global warming. Not knowing who or what to believe, the natural response for most people is to do nothing, and the consequence, as Thomas Homer-Dixon wrote last year for the New York Times: "Climate policy is gridlocked, and there's virtually no chance of a breakthrough" (2010). Meanwhile, as evidence both of the role of human contributions to global warming and the dangers of that warming continues to mount, consensus among climate scientists grows ever stronger, and those of us who attend to that evidence are increasingly alarmed.

What are climate scientists to do? Just as the strength of their claims continues to escalate, so too have attacks on their credibility, legitimacy, and even their personal safety. They were thunderstruck by the charges publicized under the name "Climategate," as was much of the broader scientific community; nothing in their training prepared them for such onslaughts, and they faced a profound dilemma. Would not engaging in public controversy over an issue now so conspicuously politicized, compromise their claim to scientific objectivity, and hence undermine their very credibility?

At first, the main response of climate scientists was to reassert the strength and legitimacy of their evidence, and to dismiss their critics as scientifically illiterate.

* Received 10 May 2011.

$\dagger$ Professor Emerita, Program in Science, Technology, and Society, MIT, Evelyn Keller works in the history and philosophy of science, with particular interests in the recent and future history of biology, climate change, and feminist theory. 
But with the escalation of attacks, many came to feel the need to "engage their critics, admit mistakes, open up their data and reshape the way they conduct their work" (Broder 2010). A last minute session, co-organized by President of the National Academy of Sciences (NAS), Ralph Cicerone, was convened at the 2010 annual meeting of the American Association for the Advancement of Science (AAAS) under the title "Ensuring the Transparency and Integrity of Scientific Research." Remarkably, reports of the session-e.g., in Science and the New York Times-laid out the problem in a manner that seemed to accept skeptics' claims about the significance of the stolen e-mail messages. While clearly critical of the media's role in sensationalizing these events, the participants agreed to accept their share of the blame, acknowledging carelessness and the need for even greater oversight on the part of the International Panel on Climate Change (IPCC). John Broder wrote for the New York Times that scientists "are learning a little humility and trying to make sure they avoid crossing a line into policy advocacy," quoting Cicerone as saying that they "must do a better job of policing themselves and trying to be heard over the loudest voices" (2010).

This response was widely seen as indicating a new willingness among scientists to engage their critics, as a step toward a more democratic relation between science and society. I am all in favor of greater engagement with the public; but am dismayed to find scientists apparently so ready to propitiate this upsurge of hostile attacks. Propitiation is not engagement. Self-criticism must not be allowed to obscure the fact that climate scientists' own confidence in their findings has not been shaken. They well know that these events were outrageously manipulated, and for blatantly political purposes. Why then such defensiveness? Why the apparent readiness of responsible media, and even of some scientists, to accept these "revelations" as evidence of misconduct-rather than, say, as evidence of the human nature of scientific inquiry? Readers are not told, for example, that the infamous IPCC error slipped through despite an extraordinary (and probably unprecedented) system of oversight that was built into the IPCC rules of procedure. The presence of such an error is evidence not of misconduct, but of the fallibility of all systems of oversight, however rigorous and demanding.

If scientists bear some responsibility, I suggest it is for their adherence to an image of science as infallible, capable of delivering absolute truth (and thus value-free)-an image that most scholars now recognize as indefensible and that, among themselves, most scientists acknowledge is unrealistic. In dealing with non-scientists, however, and especially where politics threatens to intrude, this is the image of expert authority that almost always comes into play. The assumption of a strict separation of fact from value has critically informed our traditional views about the proper relation between science and politics: the responsibility of scientists is to determine facts, untarnished by any moral, political, or religious agenda, and their role in policy making is simply to provide those facts. In this view, the only appropriate response to conflicts between science and society is 
more effective dissemination of information and improved science literacy.

Indeed, it is the very embroilment of science and policy around climate change that seems to provoke ever more insistent demands for the separation of fact and value. By contrast, I suggest that the image of a science whose authority depends on its absolute certainty and value-neutrality (a) underlies much of the confusion in the public perception; and (b) hinders climate scientists in responding effectively to the challenges they now face.

But if traditional assumptions can no longer be defended, what is to replace them? There is by now a substantial literature on the value of democratizing the relation between science and the public and enhancing dialogue among different stake-holders, most of which runs smack up against the dilemma of expertise. If we cannot draw a sharp line between knowledge and interests, then just what is the role of expertise in deliberations among different stakeholders? How are we to distinguish between legitimate and illegitimate criticism?

These questions come home to roost with such urgency in the arena of climate science because of the particular character of this science and the particular implications its claims have for us. It is precisely because the implications of climate research are so huge that the distinction between legitimate and illegitimate criticism has become so intensely politicized; it is also because of the magnitude of what is at stake that we must, somehow, find a way to make this distinction.

Clearly, we cannot do so without the help of experts. But just how much expertise is required for legitimate criticism, what ought to count as expertise, and, above all, is that expertise trustworthy? Skill, their experience and training are surely part of the answer, but Sheila Jasanoff reminds us that we also "trust experts because they supposedly represent our interests and are accountable to us, but we need to evaluate the basis for that trust from time to time" (Wheatley 2008).

Have the scientific claims about anthropogenic global warning been "proven"? Do all climate scientists agree? And if not, why should we believe these claims? Contrary to popular image, uncertainty and doubt are the daily diet of scientific researchers. On what grounds then do their conclusions warrant confidence? In the absence of a methodology for guaranteeing absolute truth, certainty and proof, working scientists employ a variety of practical measures to maximize their chances of "getting it right"-including both formal and informal criteria against which to test the quality and strength of their evidence, and a code of ethics designed to ensure the trustworthiness of their reports. Necessarily, application of these criteria requires judgment, and just in any other endeavor, good judgment depends on expertise and experience.

No scientific analysis is immune to uncertainty, but the ways in which uncertainty enters the analytic process multiply dramatically with the complexity 
of the problem under study. As everyone knows, climate change is an especially complex phenomenon and even after decades of study, our understanding of climate change remains far from complete. Climate is the product of a huge number of variables interacting over long time periods in extremely complex ways. Efforts to understand this process-to determine what variables are most important and how they interact-depend both on empirical measurements of relevant variables and on models of the physical dynamics governing their interaction, with constant exchange between the two. Recognition of the role that human activity may play complicates the task further. The resulting models require our largest computers for analysis, but they give us our best shot at understanding past, present, and future climates. The predictions they make possible are far from certain, but without them we would have no chance at all of anticipating the future; they cannot tell us what will happen, but they offer estimates of what, under various scenarios, future climates are likely to have in store for us, and with what odds.

Lay readers expecting definite answers are bound to be disappointed: but climate scientists, even when informally deploying the language of truth, by and large recognize this language as a shortcut for saying that the evidence is strong enough to warrant a working assumption of truth. Of course, judgment of just how strong the evidence needs to be for this purpose will vary, and there is ample room for debate. But the hope is that, as the evidence grows stronger, consensus can ultimately be achieved.

Importantly, scientists' confidence in their ability to contribute to the overall progress of scientific knowledge does not depend on absolute certainty or complete consensus: to resolve persistent disagreements among themselves, they rely on practices of open deliberation, collective criticism, and peer review. In relation to outsiders, however, scientific authority is not nearly so democratic. By tradition, the right to criticize is limited to those with sufficient training and research experience to evaluate the relevant evidence and arguments-such as to members of a disciplinary community who are the peers responsible for reviewing and evaluating papers for publication. Of course, members of such a community share similar viewpoints and make similar assumptions, and necessarily so. These are the assumptions that underlie the ongoing process of mutual evaluation that is a basic part of all research practice-in effect, the self-policing of the disciplinary community. They also underlie the extra levels of evaluations that have been added for the very multi-disciplinary venture we call climate science. ${ }^{1}$ Finally, it is because their claims have survived all these levels of scrutiny that most climate scientists have the confidence they have in their measurements, calculations and predictions. Yet, even so, there is still dissent, and even so, they could still be

1 First and foremost, for the IPCC, and second, for the independent reviews undertaken by national committees such as the NAS. 
wrong.

What most worries so many climate scientists, however, is not the possibility that they could be wrong, but the magnitude and seriousness of the implications of their findings should they be right. No one knows how bad things could get-how hot, how flooded, how drought-stricken, how unstable-nor can anyone say whether the cost in human lives by the end of the century, should we fail to act now, is likely to be in the tens or hundreds of millions (or even billions). We only know that the most likely consequences would be horrendous.

How large a risk, then, are we willing to tolerate? This question points to the vital difference between climate change and other familiar clashes between science and politics that are sometimes invoked as parallels: evolutionary theory, for example, or theories of planetary motion. Neither the future of evolution nor of planetary motion depends on what people believe about these theories. Here, however, the future may depend critically on what people believe, and hence are willing to do. Indeed, it is the link between belief and action on the one hand, and the magnitude of the potential consequences of inaction on the other, that set climate science apart. And accordingly, that oblige us to juxtapose the questions, what if climate scientists are wrong and what if the investment we would have to make in retooling our economy and reducing emissions proves not to have been necessary, with the complementary questions: what if the skeptics are wrong? Just how much devastation are we willing to risk? Yet this is precisely the question that is muted and deflected by the campaign to promote doubt.

So how should climate scientists respond? Confident that they have the expertise to distinguish between information and misinformation, they are generally dismayed by the diffusion of blatant misinformation. But if readers are not prepared to grant them authority, what can they do? Their commitment to resolving their own disagreements internally, their formal gate-keeping mechanism of peer review, establishes a base line of reliability and grounds their expertise; although the outcome is not absolute, it has passed the most stringent tests available. But this, now, is clearly not enough.

The view of scientific authority as resting exclusively on internal evaluation inevitably discourages scientists' engagement with lay critics; to the extent that their authority depends on separating science from politics, fact from value, venturing into the public domain may seem to put their very credibility at risk. Yet there are obvious problems with such restraint. For one, internal reliance on peer review leaves unaddressed the question of what is to be done about the free dissemination of misinformation. Peer-reviewed journals (which preponderantly support the conclusions of the IPCC) are not read by the non-specialist audiences that climate scientists most need to reach. Such audiences vary greatly, but they share an insulation from the professional literature that greatly contributes to the skepticism we are now seeing. 
There are also other problems. Recourse to peer review for final judgment of the technical contents of a paper is a familiar response; but should the internal regulatory system of scientific disciplines exclude all external criticism? Can no one from outside raise objections, register doubts, engage in productive criticism? Not even Freeman Dyson? What qualifications must a non-specialist reader have for legitimate engagement in critical review?

Which brings us back to the relation between science and politics. Citing Carl Schmitt's Concept of the Political, Stephen Turner argues that expert claims are already "political" to the extent that they "affect, combat, refute, and negate' ... some faction or grouping of persons" $(2007,36)$. That criterion would certainly apply to specialists' claims about the human contribution to climate change. But then a political statement is not ipso facto either non-scientific or untrue. Indeed, in good part it is just because the foreseeable advantages or disadvantages of different groups of people depend so critically on scientific "facts" that the relations between science and politics are as fraught as they are.

Quotation marks are necessary here because calling something a "fact" can itself be a political move, as in the suggestion that "experts just recuse themselves when they don't really have the facts to warrant a policy" (Taylor 2007, 39-40). If what science deals with are the product of our best efforts at getting it right, and hence always subject to some degree of uncertainty, the demand that "facts" be parsed from "uncertain claims" and "beliefs" is dubious at best. Scientific reasoning depends on beliefs, ideas, guesses, and uncertain inferences that are essential parts of the specialists' efforts to "get it right." But crucially, the beliefs, ideas, guesses, and inferences are informed; they are constrained by what is already known of the matter in question, and by the ongoing critique and possible refutation they routinely must face.

Policy too, in the normal course of events, is warranted not only by demonstrable facts but also by estimates of what is likely, by inferences from available data, and even by informed guesses. Military policy, economic, health, and welfare policy, cannot afford to wait for "proof," but must be arrived at on the basis of the best information available. If the experts on whom policy makers rely were to recuse themselves whenever they didn't "really have the facts," policy would be in a sorry state indeed.

Given the scope and gravity of the social implications of scientists' claims about climate change, there is no way to separate the claims from their political implications-just as there is no separating political arguments from assertions about what is or is not the truth of the matter. In other words, it is effectively impossible to separate scientific analysis from the likely consequences of that analysis. Perhaps we would better manage these tensions if we admitted our political need for special scientific expertise, just as we admit our need of expertise in all other areas of our lives. 
The particular authority that climate scientists can fairly claim requires more than expertise as such: it also requires legitimation, and at least in the United States, that legitimation is normally provided by peer-review and resides within the disciplinary community. How can it be extended into the public domain? And what new responsibilities does such extension entail?

Discussions of scientific responsibility often begin with questions about a scientist's responsibility to other scientists: that is, with issues of scientific integrity. But scientists also have obligations incurred by the trust the public has invested in them qua scientists. Scientific responsibility must also include that which derives from their implicit contract with the state that funds them: a contract that makes the product of their labor a public good. For as long as the scientific knowledge they produce remains under their own control, they are its custodians; they are responsible for its safe delivery into public hands. I am arguing, in short, that their responsibility, qua scientists, must include the obligation to convey the results of their expertise to those likely to be affected by the implications of those results. Clearly, the consequences of global warming-both their magnitude and their dependence on human behavior-lend this obligation particular gravity in the case of climate change. But how is this obligation to be discharged, without undermining the scientist's hard won claim to disinterested objectivity?

The prevailing view is that scientific authority comes from the validation of a disciplinary community. But there is no obvious reason why such validation should automatically endow experts with public authority. Seen from outside their community, something more is required. In the absence of technical expertise of my own, I need to be persuaded both of the honesty (or credibility) of my informant, and of the cogency of her argument.

Within the scientist's discipline, validation and respect is won on the basis of sound arguments and authenticated evidence. Why cannot these same considerations also legitimate authority outside their own community? Is technical expertise really necessary for engaged readers to distinguish between good arguments and bad? Between carefully collected and well-scrutinized evidence on the one hand and conspicuously flimsy evidence on the other? To improve public understanding, the standard response is increased science literacy. But I would argue that even more needed is increased articulacy on the part of scientists; an increased effort to make their arguments, their doubts, and the reasons for their concern intelligible to the non-specialist citizen. That effort is rarely as difficult as is generally assumed: disagreements and uncertainties are familiar territory to most readers, and examples in which technical arguments are made accessible are not hard to find. Effective communication requires an ear for what readers need, and one thing they need is to be given access to the process by which so many climate scientists have reached the conclusions they have, within the limitations of their knowledge and the uncertainties of their 
projections. Even readers without the relevant technical background can make the sorts of discrimination needed to establish trustworthiness.

In other words, I am arguing that, where the results of their work have direct impact on the public, scientists have a particular responsibility both to provide a candid, accessible, and meaningful account of their findings and the implications of those findings to that public, and to respond to whatever concerns persist. I see no reason why this responsibility need in any way conflict with scientists' responsibility to their peers, nor do I see any reason why they cannot draw on the professional authority they have already established in extending that authority to a wider audience. When Freeman Dyson complains to readers of the New York Review of Books that climate scientists tend to exaggerate the dangers of climate change (see, e.g., Dyson 2008), these scientists have a responsibility to respond. Perhaps more urgently, it is their responsibility to combat, piece by piece, the misrepresentations brought in support of the recent attacks on the integrity of climate scientists and of the IPCC, and to show readers just why the popular accounts and even the very naming of "Climategate" are so misleading.

What I am proposing is far from a solution. But if it succeeds in encouraging climate scientists to take the lead in breaking through our current impasse-both because they are best placed and equipped to take on the task, and because their responsibility qua scientists obliges them to do so-it is a start.

\author{
Evelyn Fox Keller \\ Program in Science, Technology, and Society \\ MIT \\ Cambridge MA 02139 \\ efkeller@mit.edu
}

\title{
References
}

Broder, John M. 2010. Scientists Taking Steps to Defend Work on Climate. New York Times. March 2. http://www.nytimes.com/2010/03/03/science/earth/03climate.html.

Dyson, Freeman. 2008. The Question of Global Warming, New York Review of Books, June 12, 2008.

Homer-Dixon, Thomas. 2010. Disaster at the Top of the World. New York Times. August 22.

Turner, Steven. 2007. Political Epistemology, Experts and the Aggregation of Knowledge. Spontaneous Generations 1(1): 36-47.

Wheatley, Claudia. 2008. Harvard professor says U.S. administration is at fault for public's skeptical view of science. Cornell Chronicle Online. September 5. http://www.news.cornell.edu/stories/Sept08/Jasanoff.cover.cw.html. 